\title{
PROBLEMATIZANDO A IMPOSIÇÃO DE CORPOS FEMININOS DESEJÁ VEIS NAS HISTÓRIAS EM QUADRINHOS DA TURMA DA MÔNICA JOVEM
}

\author{
PROBLEMATIZING THE IMPOSITION OF DESIRABLE FEMALE BODIES \\ IN THE STORIES OF MONICA TEEN
}

\section{PROBLEMATIZANDO LA IMPOSICIÓN DE CUERPOS FEMENINOS DESEABLES EM LAS HISTORIAS DE LA SERIE TURMA DE MÓNICA JOVEN}

\author{
Sandra Nazaré Dias Bastos ${ }^{1}$; Marcos Allan da Silva Linhares ${ }^{2}$; Lêda Valéria Alves da Silva
}

\begin{abstract}
Resumo
O objetivo desse trabalho é analisar discursos que produzem o corpo feminino anormal em histórias em quadrinhos da Turma da Mônica Jovem. Utilizamos ferramentas teóricas propostas por Michel Foucault para olhar como personagens femininos "acima do peso" são mostrados. Verificamos que os enredos acionam diferentemente os gêneros feminino e masculino e embora levantem temas como bullying e distorção da imagem reforçam estereótipos que convencionalmente associamos ao corpo gordo. Ao problematizar como ensinamos o corpo nas aulas de Biologia sugerimos que é preciso desnaturalizar os agenciamentos que reforçam a padronização corporal como meta. É necessário investir em uma educação de ecdises e caminhos docentes que nos levem a recusar prescrições que cotidianamente nos impõem modos uniformizados de ser gente.
\end{abstract}

Palavras-chave: Ensino de Ciências; Análise do Discurso; Pedagogias Culturais; Relações de Gênero; Formação de Professores.

\begin{abstract}
The objective of this work is to analyze speeches that produce the abnormal female body in the comic books Monica Teen. We use theoretical tools proposed by Michel Foucault to analyze how "overweight" female characters are shown. We found that the plots trigger female and male genders differently and although they raise issues such as bullying and image distortion, they reinforce stereotypes that we conventionally associate with the fat body. When discussing how we teach the body in Biology classes, we suggest that it is necessary to denaturalize the assemblages that reinforce body standardization as a goal. It is necessary to invest in an education of ecdyses and teaching paths that lead us to refuse prescriptions that daily impose uniform ways of being people.
\end{abstract}

Keywords: Science Teaching; Discourse Analysis; Cultural Pedagogies; Gender Relations; Teacher Education.

\footnotetext{
${ }^{1}$ Doutora em Educação em Ciências e Matemáticas - Universidade Federal do Pará (IEMCI/UFPA). Belém, PA Brasil. Professora do Instituto de Estudos Costeiros (IECOS/UFPA) - Faculdade de Ciências Biológicas. Docente do Programa de Pós-graduação em Linguagens e Saberes na Amazônia (PPLSA/UFPA), Campus Universitário de Bragança. Belém, PA - Brasil. E-mail: sndbastos@gmail.com

${ }^{2}$ Mestre em Educação em Ciências e Matemáticas - Universidade Federal do Pará (UFPA). Belém, PA - Brasil. Professor das disciplinas de Ciências e Biologia no Centro Educacional João Paulo II (Bragança/PA). Faz parte do Grupo de Estudos e Pesquisas em Cultura e Subjetividade na Educação em Ciências (GEPECS-UFPA). Belém, PA - Brasil. E-mail: marcosallan.18@gmail.com

${ }^{3}$ Doutora em Educação em Ciências e Matemáticas pela Universidade Federal do Pará (UFPA). Belém, PA Brasil. Faz parte do Grupo de Estudos e Pesquisas em Cultura e Subjetividade na Educação em Ciências (GEPECSUFPA). Belém, PA - Brasil. E-mail: leda_valeria@yahoo.com.br
} 
DOI: http://doi.org/10.46667/renbio.v14i1.534

\title{
Resumen
}

El objetivo de este trabajo es analizar discursos que producen el cuerpo femenino anormal en historias de series de dibujos como en la "Turma de Mónica Joven”. Utilizamos herramientas teóricas propuestas por Michel Foucault para ver como personajes femeninos "exceso de peso" son mostrados. Verificamos que los argumentos accionan de manera diferente entre los géneros femenino y masculino, aunque levanten temas como bullying y distorsión de imagen que refuerzan estereotipos que convencionalmente asociamos al cuerpo gordo. Al problematizar como ilustramos el cuerpo en las clases de Biología sugerimos que es necesario desnaturalizar las razones que refuerzan al estereotipo de género como meta. Es necesario invertir en una educación de ecdisis y caminos docentes que nos lleven a recusar prejuicios que cotidianamente nos imponen modos uniformizados de ser gente.

Palabras clave: Enseñaza de Ciencias; Análisis de Discurso; Pedagogías Culturales; Relaciones de Género; Formación de Profesores.

\author{
**** \\ O corpo: superfície de inscrição dos acontecimentos \\ Michel Foucault - A Microfísica do Poder \\ Tem que correr, tem que suar, tem que malhar (vamos lá!) \\ Musculação, respiração, ar no pulmão (vamos lá!) \\ Tem que esticar, tem que dobrar, tem que encaixar (vamos lá!) \\ Um, dois e três; é sem parar, mais uma vez! \\ Marcos Vale - Estrelar
}

\section{0 que você mudaria no seu corpo?}

A pergunta acima foi uma provocação aos alunos de uma turma de formação de professores para o ensino de Ciências. Sem a condicional "se você pudesse" o princípio afirmativo de que todos teriam alguma coisa a mudar, nos mostrou em linhas gerais que todos, sem exceção, mudariam alguma coisa em seus corpos. Mas, o quê, especificamente os professores mudariam em sua aparência? E, por que, a possibilidade de mudança foi aceita sem nenhum questionamento?

A ideia de fazer essa provocação partiu de situações cotidianas e repetitivas que nos acionam enquanto corpo que 'precisa' mudar para um tipo 'padrão' específico. As imagens reunidas na Figura 1 nos fornecem um indicativo da materialização desse discurso: corpo perfeito $=$ corpo magro $=$ corpo sarado $=$ corpo a ser transformado. 
DOI: http://doi.org/10.46667/renbio.v14i1.534

Figura 1: Corpo perfeito $=$ corpo magro $=$ corpo sarado $=$ corpo a ser transformado

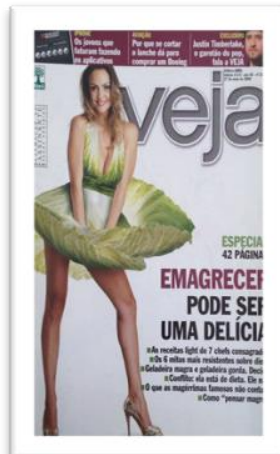

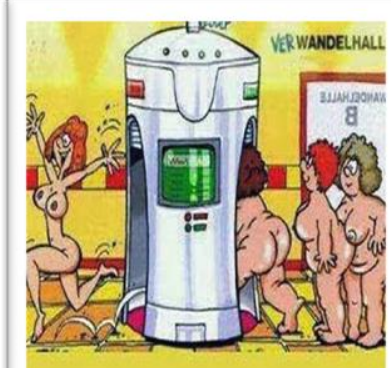

Máquina dos sonhos!
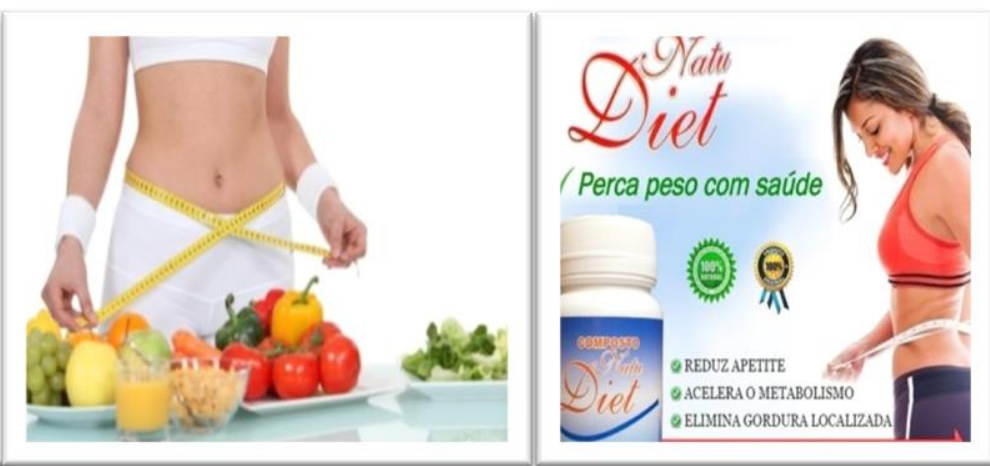

Fonte: https://macmagazine.com.br/post/2009/05/25/fingertips-marca-presenca-em-novela-da-rede-globo-e-nacapa-da-revista-veja/; http://odiariodaalegria.blogspot.com/2014/03/maquina-dos-sonhos-de-muitasmulheres.html; https://www.ung.br/noticias/nao-caia-em-falsas-promessas-de-emagrecimento; https://epocanegocios.globo.com/Empresa/noticia/2015/12/anvisa-suspende-fabricacao-e-propaganda-irregularde-produto-emagrecedora-materia.html.

Em princípio, nenhuma das imagens nos é estranha. Elas se apresentam aos nossos olhos, como em um imenso cardápio repetitivo, nas capas de revistas semanais, em propagandas impressas, em sites de busca, outdoors, charges da internet. Não nos causa incômodo que os corpos sejam femininos, brancos, magros e que mostrem que a transformação de um corpo 'gordo' em um corpo esguio possa ser sinônimo de felicidade.

Segundo uma pesquisa divulgada em 2019, pela Sociedade Internacional de Cirurgia Plástica e Estética (ISAPS), o Brasil é um dos países que mais realiza procedimentos estéticos invasivos e do total a maioria são mulheres e, cada vez mais jovens ${ }^{4}$. Nossa provocação, então, consiste em perguntar: Como passamos a desejar esse corpo, que não é o nosso, mas que é um 'corpo possível', 'desejável' e acima de tudo, uma meta a ser alcançada?

Atualmente o investimento na busca de um corpo perfeito nos é apresentado em um sem número de materialidades que reforçam por meio de programas de televisão, revistas, documentários, séries, livros, embalagens de alimentos, postagens nas redes sociais que é possível "auxiliar" as pessoas que desejam se dedicar na "luta" por um corpo "ideal".

No Instagram ${ }^{5}$ é possível encontrar inúmeras contas relacionadas à uma suposta vida saudável em que as pessoas são convidadas constantemente a seguir dietas e exercícios para ter um corpo ideal. Nelas, as mulheres são a maioria esmagadora e se amontoam nos comentários respondendo: "eu quero!" para a pergunta: "você deseja receber receitas (ditas milagrosas) e exercícios (supostamente corretos) para ter um corpo ideal?". Ali, a capacidade de reação é testada e ao mesmo tempo frustrada pela impossibilidade do "milagre" prescrito.

\footnotetext{
${ }^{4}$ Disponível em: https://www.isaps.org/wp-content/uploads/2020/12/ISAPS-Global-Survey-2019-Press-ReleasePortuguese.pdf.

${ }^{5}$ Rede social on line de compartilhamento de fotos e vídeos.
} 
DOI: http://doi.org/10.46667/renbio.v14i1.534

$\mathrm{O}$ que acontece na rede social e as imagens mostradas anteriormente formam um conjunto diverso de acionamentos que ligam em muitas mulheres o desejo de ter aquele corpo, de ser daquele jeito. Não a propósito as respostas à pergunta que fizemos aos alunos-professores se limitaram a um único tipo de resposta: eu teria um abdômen "sarado" ou, mais simplesmente, uma barriga tanquinho.

Afinal, por que deveríamos nos inspirar naquela pessoa ou naquele corpo que estava na imagem? Como aquele corpo se tornou fonte de inspiração, ponto de chegada, objeto de desejo e sonho de consumo?

Olhando para tudo isso, é possível perceber que todo esse material compõe um arsenal midiático que tem investido seu tempo e suas produções na definição de um corpo "inspirador". As imagens não são "só" imagens! Elas fazem parte de uma teia pedagógica que nos ensina eficientemente o que devemos desejar, no que devemos nos transformar e o que deve nos inspirar.

O Instagram, entre tantos outros dispositivos culturais, como filmes, desenhos animados, revistas semanais e em quadrinhos, funcionam, como nos diz Garré et al (2014), como ferramentas potentes para difundir saberes e verdades acerca dos nossos comportamento, regulando, legitimando e nos ensinando, entre outras coisas, qual tipo de corpo devemos desejar a fim de suplantar uma suposta falta, mas "que falta é essa que produz um desejo tão profundo, a ponto de ser confundido com uma dita essência, com uma verdade e, por consequência, uma verdade humana?" (DULCI, 2011, p. 254).

Vemos meninas/mulheres sendo transformadas em máquinas desejantes que não medem esforços para ultrapassar todos os limites que as afastam daquele corpo que pensam para si. De tal forma que chegam ao ponto de naturalizar dietas mirabolantes, os infindáveis exercícios abdominais, a bulimia e a anorexia... Esses problemas (na verdade, patologias) nos mostram toda coerção social sobre o corpo feminino, que se torna vítima de idealizações largamente difundidas pelos meios de comunicação de massa (BRAGA, 2009).

Para além dessas materialidades é conveniente problematizar também como conduzimos nossa ação docente: Como nós, professores de Ciências, por meio dos conteúdos que ensinamos, temos atuado no reforço e manutenção desses estereótipos femininos? O corpo que temos ensinado em nossas aulas acionam nas mulheres o desejo desenfreado de ter um corpo dito ideal? Que tipo de saberes estamos produzindo e fazendo circular? Problematizamos os estereótipos femininos que estampam nossos livros didáticos? Investimos na problematização de corpos femininos diversos que não se encaixam ou não cabem no "padrão" que reiteradamente aprendemos a enxergar como "normal"? 
DOI: http://doi.org/10.46667/renbio.v14i1.534

Neste texto, não pretendemos fazer apologia a nenhum tipo de corpo, seja ele dito gordo/magro, bonito/feio, mas fazer estremecer a velha sintaxe com que fomos atravessados fazendo com que os corpos ditos fora do padrão se tornassem sinônimo de doença e baixa autoestima, que faz com que muitas mulheres sejam fagocitadas pela promessa de um corpo perfeito, arriscando até mesmo a vida para chegar a um ideal prescrito a priori e que aprendemos a enxergar como natural. É preciso diferenciar o cuidado com a saúde da modulação subjetiva que captura o desejo e faz querer vestir um corpo que não nos cabe, sob o pretexto de uma vida supostamente feliz.

Diante dessas situações e questionamentos, temos como o objetivo principal nesse trabalho analisar alguns enunciados discursivos que produzem o corpo feminino fora da norma - o corpo anormal - nas histórias em quadrinhos da Turma da Mônica, procurando descrever de que forma esse corpo é acionado para se enquadrar em um determinado padrão que é dito "normal".

\section{As histórias em quadrinhos e o Ensino de Ciências: desenhando percursos metodológicos}

O ramo das histórias em quadrinhos (HQs) tem crescido no Brasil, tendo como público consumidor os mais variados tipos de pessoas e faixas etárias agradando tanto crianças quanto jovens e adultos. Não mais compartilhadas sorrateiramente e escondidas nos intervalos escolares elas assumem o protagonismo das aulas sendo utilizadas para ensinar conteúdos e incentivar o hábito da leitura.

$\mathrm{Na}$ academia muitos pesquisadores têm investido seu tempo e sua escrita no potencial das HQs na educação em Ciências. A revisão bibliográfica realizada por Pizarro (2017) aponta que esse material foi objeto de 27 trabalhos entre 1997 e 2015 em um dos principais eventos na área da Educação em Ciências do Brasil ${ }^{6}$. Os trabalhos apresentados apontavam a possibilidade do uso dos quadrinhos como recurso didático tanto na educação básica quanto na superior, não só para a abordagem de conteúdos em diversos campos da Ciência, mas também como possibilidade de incentivar e desenvolver a leitura e análise de textos, criação de quadrinhos, discussão de história da ciência e como mecanismos de avaliação. É possível perceber ainda que, de forma bastante diversificada, esse material tem circulado em nossas salas de aula para ensinar conteúdos específicos de outras áreas do conhecimento como: Linguagens (SPICACCI, 2018), Ciência da Informação (OLIVEIRA, 2014) e Matemática (SANTOS-JÚNIOR, 2010).

Em que pese que muitas escolas têm se utilizado das HQs para o ensino de conteúdos por esse material se apresentar como "currículo cultural capaz de divertir, sentir, viver [...] e poder ser aplicado nos mais diversos conteúdos escolares" (ALCÂNTARA, 2014, p.07), vamos tomá-lo para além do uso escolar e discutir como as histórias se configuram como parte de uma ${ }^{6}$ O levantamento realizado pelo autor analisou os trabalhos apresentados no Encontro Nacional de Pesquisa em
Educação em Ciências - ENPEC. 
DOI: http://doi.org/10.46667/renbio.v14i1.534

eficiente maquinaria de produção de identidades. Além de auxiliarem a ação pedagógica dos professores, elas transbordam do universo escolar e nos ensinam lições mais complexas. Ao fazerem parte do cotidiano de nossos alunos, de suas vidas e de suas rotinas, ensinam-lhes modos de ser, estar, viver e se comportar na sociedade por meios de seus discursos.

Tomamos como materialidade de estudo revistas da Turma da Mônica, principalmente das coleções Turma da Mônica Jovem (TMJ) e Chico Bento Moço (CBM) que são produzidas pela Maurício de Sousa Produções (MSP) desde 2008 e que contam as histórias da turma enfrentando problemas e dilemas a partir da adolescência. A partir desse ano, vários outros trabalhos envolvendo os personagens de Maurício vêm ganhando ainda mais espaço na mídia brasileira como filmes, graphic novels ${ }^{7}$, animações, jogos e etc.

Tomamos esse material em particular, pois se destinam ao público pré-adolescente. Algumas edições da TMJ tiveram tiragens superiores a 500 mil exemplares, fazendo dessa produção uma das mais vendidas no mundo ${ }^{8}$, além disso, elas também podem ser encontradas em inglês e espanhol. As revistas da coleção CBM também são consideradas sucesso de venda. A primeira edição, em 2013, teve tiragem inicial de 150.000 exemplares, que esgotou rapidamente. Para solucionar esse problema uma tiragem adicional de 50.000 exemplares foi providenciada 9 .

Diante do vasto público que atinge, achamos pertinente problematizar como o corpo adolescente aparece nessa produção, uma vez que os efeitos que essas histórias produzem vão para além do entretenimento. Consideramos esse material como poderoso artefato cultural que produzem e constituem os sujeitos que as leem. Por esse motivo é importante tomá-las como instâncias pedagógicas na cultura contemporânea que atuam na disseminação de discursos não apenas em nossas casas, mas também em hospitais, salas de espera de consultórios, nas escolas e em muitos outros espaços públicos.

Para análise desses discursos utilizamos as ferramentas teóricas propostas por Michel Foucault que defende a ideia de que os discursos são práticas que determinam o que pode ou não entrar na ordem dos discursos sobre os corpos e, por conseguinte, ditar o que deve ser considerado verdade a partir de sua vontade. Essas práticas discursivas, como afirma Foucault (2007, p.133), nada mais são do que um conjunto de regras históricas que estão inscritas em determinado tempo e espaço, que definem em cada época e em cada área de nossa sociedade as condições de possibilidade para que a função enunciativa desses discursos possa aparecer e funcionar. São essas práticas discursivas acerca do corpo que definem o que é um corpo admitido como bonito, saudável e que deve ser assumido como padrão a ser desejado e copiado. Sustentando esses discursos vemos aparecer as práticas que, direcionadas à educação e disciplinamento de nossos corpos, tais como necessidade de exercícios físicos e a adoção de

\footnotetext{
${ }^{7}$ Segundo Carvalho (2018, p.18), graphic novels são histórias em quadrinhos que trazem em seu interior temáticas mais importantes para discussão do que as histórias em quadrinhos "tradicionais" como, por exemplo: representações de gênero, raça, etnia, etc.

${ }^{8}$ Informações disponíveis em: https://pt.wikipedia.org/wiki/Turma_da_M\%C3\%B4nica_Jovem\#cite_not

${ }^{9}$ Informações disponíveis em: $\underline{\text { https://pt.wikipedia.org/wiki/Chico_Bento_Mo\%C3\%A7o }}$
} 
DOI: http://doi.org/10.46667/renbio.v14i1.534

dietas rigorosas com a utilização de produtos light/diet, nos levam à adoção de um estilo de vida que é dito saudável ou simplesmente fitness.

Em busca dos enunciados que prescrevem esse estilo de vida, não nos restringimos a uma série contínua de revistas. Lançamos nosso olhar para os lugares em que os personagens da TMJ e CBM apareciam ou onde se falava dos corpos fora do padrão, independente da edição ou data. Para mostrar a sustentação desses discursos, olhamos ainda para as suas vizinhanças, ou seja, para outros artefatos culturais que compõem a rede enunciativa que garante a dispersão e regularidade discursiva.

Esse trabalho traz como corpus de análise as edições 33 (2014) e 45 (2016) da TMJ e as edições 01 (2013), 02 (2013) e 14 (2014) da CBM, que foram lidas na íntegra para análise não apenas do enredo, mas também das imagens. A análise das imagens, que em primeira vista pode remeter a algo corriqueiro e cotidiano, é importante para nos fazer pensar e problematizar como os personagens são personificados. Como afirma a autora, é justamente por esse caráter despretensioso que normalmente usamos para nos referir às imagens que devemos cada vez mais estudá-las e discutir junto com outras pessoas como as consideramos e as olhamos dentro do espaço escolar como afirma (MARCELLO, 2013, p.13).

Milanez (2013) defende que a imagem pode ser tratada como enunciado, tal como concebeu Foucault. Para isso é necessário buscar descrever as condições de possibilidades que fizeram com que elas aparecessem em um determinado tempo e espaço. Pautado no fundamento da intericonicidade, que é a rede de reminiscências pessoais e de memórias coletivas que religam as imagens umas às outras, Courtine (2013) explica que toda imagem estende ramificações genealógicas na memória das imagens. Toda imagem, suscita outra. Tomar as imagens dessa forma implica vê-las como produtoras e produtos de um determinado discurso e consequentemente, que produzem modos de ver e pensar sobre o corpo (OLIVEIRA, 2016).

\section{O "peso" de um "problema" 10 ...}

A maioria de nós cresceu lendo as histórias da Turma Mônica e acompanhando as aventuras geradas a partir dos planos infalíveis do Cebolinha para capturar o Sansão. Também acompanhamos, entre risadas, as surras geradas a partir dos desenhos rabiscados nos muros do bairro mostrando a figura da Mônica de forma estereotipada com traços desproporcionais que acentuavam suas medidas corporais. No entanto nunca nos perguntamos por que, embora todos os personagens tenham uma conformação corporal muito parecida, só a Mônica é chamada de gorducha! E por que ser adjetivada dessa forma, é motivo de ofensa?

\footnotetext{
10 Título de uma história em quadrinho da série "Turma da Mônica Jovem", n 33. Produzido por: Panini Comics. Ênfase na palavra 'problema' dada por nós.
} 
DOI: http://doi.org/10.46667/renbio.v14i1.534

$\mathrm{Na}$ TMJ os personagens principais passam por mudanças corporais significativas, deixando para trás o corpo criança e as desavenças do passado. Mônica é assim descrita: "Alegre, meiga e ainda um pouco dentucinha [...] se tornou uma garota esbelta e muito bonita". Magali, sua melhor amiga, também sofreu modificações em sua forma de agir, sendo assim apresentada: "Hoje mais controlada, segue uma reeducação alimentar para manter-se saudável" "1 . A forma de descrever Cascão e Cebolinha é diferente. Eles também cresceram e se tornaram rapazes "descolados", "inteligentes", "espertos", "criativos", mas, com suas características corporais da infância silenciadas em qualquer descrição. Não pesa sobre eles uma conduta corporal, que questionasse a forma de seus corpos e hábitos.

Esse novo tipo corporal que confere beleza aos personagens na atualidade e marca a outra fase da turma é transposto para a nova aparência dos personagens que assumem as características de um "padrão" corporal mais alto e esguio (Figura 2).

Figura 2: Turma da Mônica e Turma da Mônica Jovem
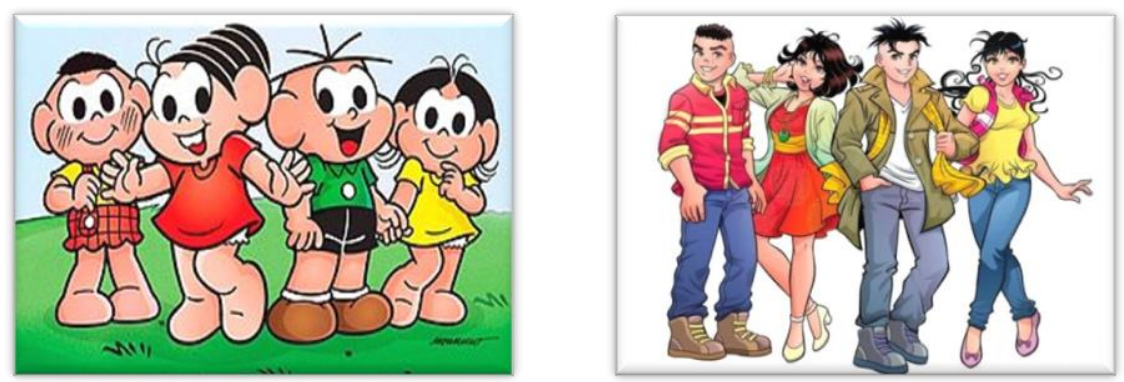

Fonte: http://turmadamonica.uol.com.br/personagem/monica-jovem/ e https://pt.wikipedia.org/wiki/Turma_da_M\%C3\%B4nica.

Na história “O peso de um Problema”, presente dentro da Turma da Mônica, a trama gira em torno da personagem Isa, garota nova na escola e que chega chamando a atenção para sua aparência "acima do peso". Embora seja uma adolescente alegre, cordial e bem resolvida com seu corpo ela é imediatamente rejeitada pelas meninas vaidosas do grupo. Uma delas, Maria, tem problemas com sua imagem e faz regimes rigorosos para manter a aparência sempre em “ordem”. Rapidamente Isa se torna seu principal pesadelo. Parecer com ela é algo tão absurdo que ela chega a desmaiar quando confunde seu reflexo com o de Isa no que pensa ser um espelho (Figura 3).

\footnotetext{
${ }^{11}$ Apresentação das personagens: informações disponíveis em: https://pt.wikipedia.org/wiki/Turma_da_M\%C3\%B4nica_Jovem (grifos nossos)
} 
Figura 3: Chegada de Isa na Escola
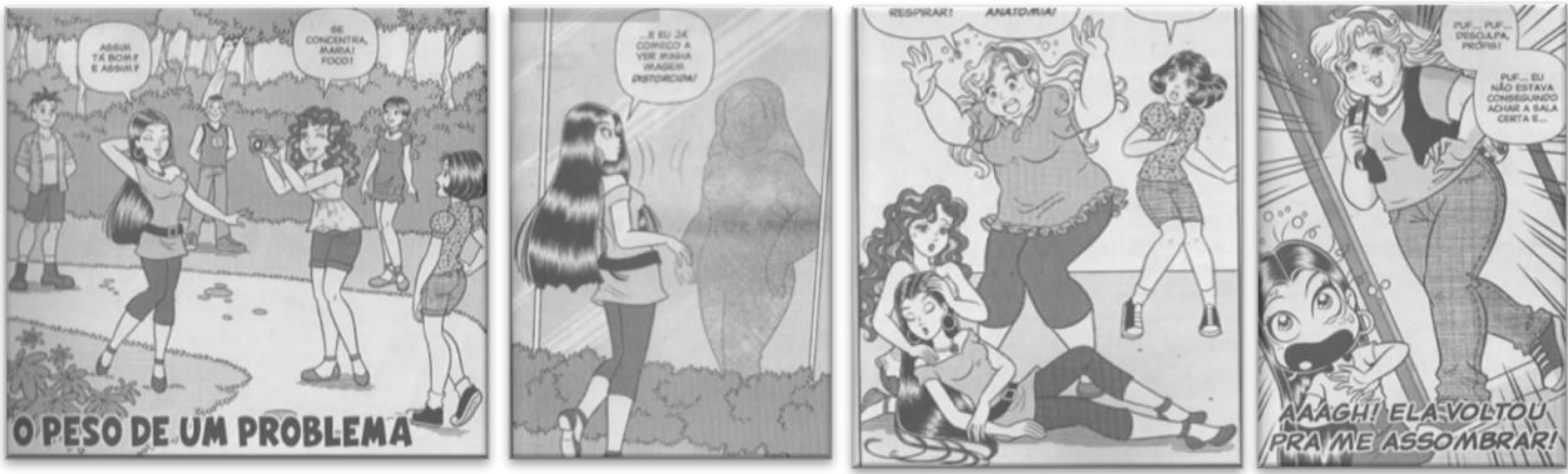

Fonte: Turma da Mônica Jovem, nº 33, Panini Comics.

Por um lado, algumas meninas gostam de tê-la por perto para parecerem mais bonitas e mais magras ao seu lado. Ao contrário do grupo feminino, os meninos promovem bullying de forma mais "discreta" e "velada" sussurrando frequentemente insinuações sobre a aparência ou a falta de jeito da personagem em algumas situações. Em uma festa organizada pelo grupo todos riem da forma com que Isa, de forma descontraída e alegre dança com um Xaveco extremamente constrangido. De maneira geral todos se incomodam com a quantidade (sempre muito farta) e a qualidade de alimentos que Isa consome. A cada refeição vemos acionada uma "patrulha" que na forma de repreensões nem sempre sutis questiona, monitora e comenta o que ela coloca no prato (Figura 4).

Figura 4: Prato cheio: Alimentação de Isa
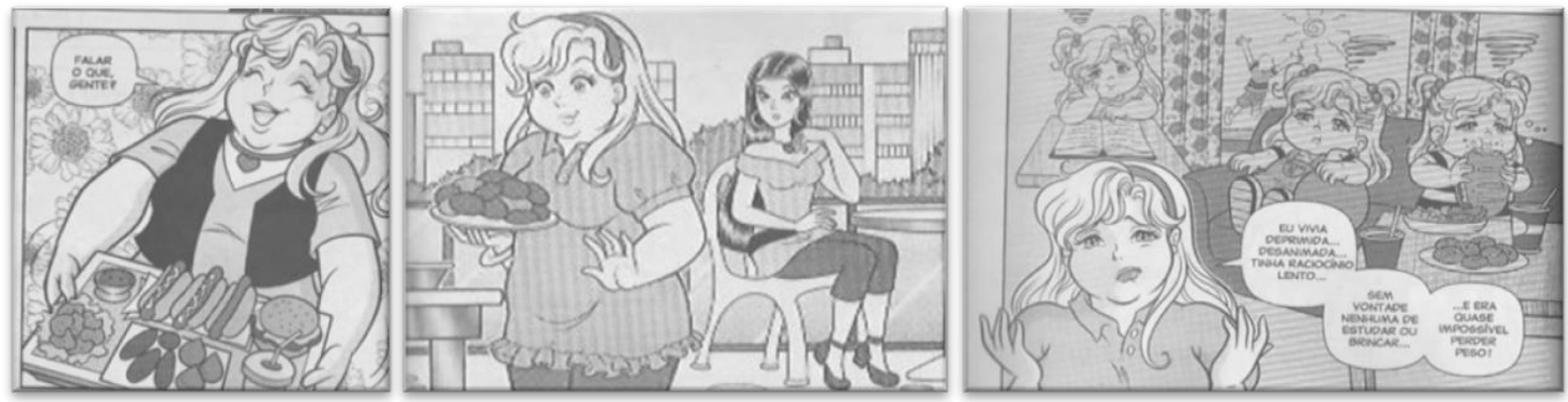

Fonte: Turma da Mônica Jovem, nº 33, Panini Comics

Tentando ser aceita mais rapidamente pelo grupo, ela cede aos insistentes conselhos que a direcionam a perder peso, e com isso, ter uma vida "mais saudável". Prática de esportes, exercícios físicos e dieta são os mecanismos colocados à sua disposição para alcançar seu objetivo de forma rápida e eficaz. Isa a todo o momento aparece esbaforida, despenteada, seu corpo reflete o sacrifício que é incorporar as práticas de emagrecimento. Os demais membros do grupo não parecem empreender tanto esforço, não há dificuldade em fazer uma corrida ao ar livre ou levantar alguns pesos. Até mesmo uma pessoa com dificuldades de locomoção (Luca, um cadeirante) consegue se sair melhor que Isa na realização dos exercícios físicos (Figura 5). 
DOI: http://doi.org/10.46667/renbio.v14i1.534

Figura 5: Isa praticando esportes com a turma
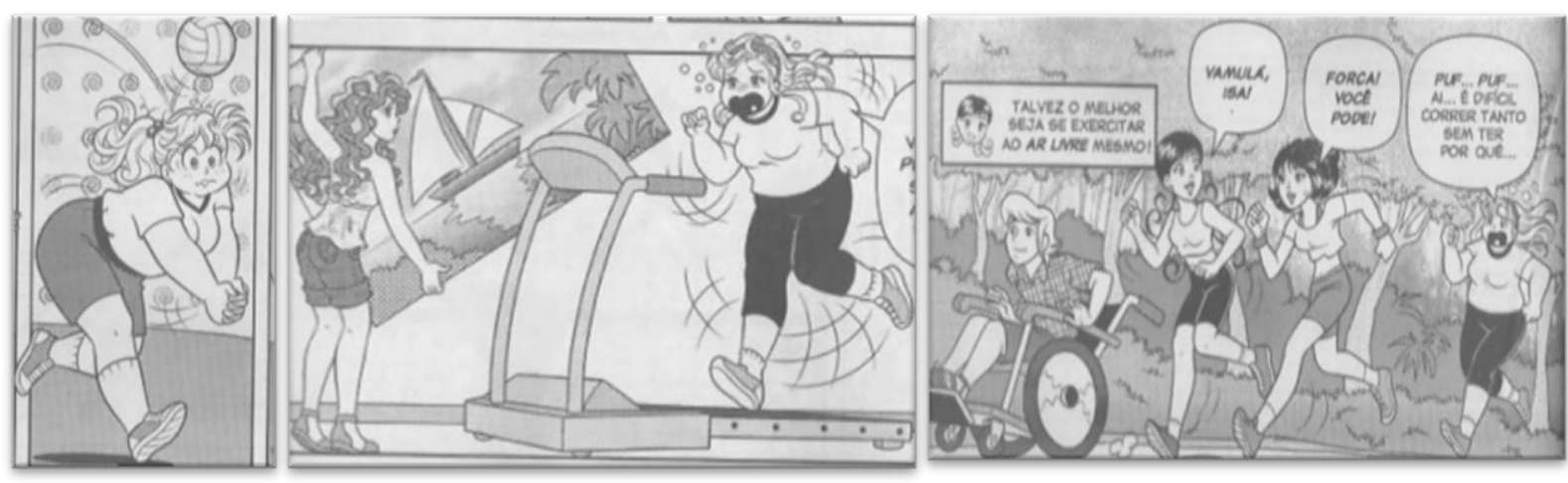

Fonte: Turma da Mônica Jovem, nº 33, Panini Comics.

Embora o enredo levante temas importantes para discussão como: distorção de imagem, aceitação, discriminação, preconceito e gordofobia a trama acaba reforçando alguns dos muitos estereótipos que convencionalmente associamos ao corpo gordo. O consumo exagerado de comida é associado à compulsão alimentar que por sua vez, reforça o enunciado de que o corpo gordo não tem autocontrole. As imagens mostram que para Isa, tudo é muito mais difícil e daí é possível formular os seguintes questionamentos: Como é possível ela não se importar com sua aparência? Por que ela não consegue emagrecer em um mundo em que as dietas e os programas de exercícios estão disponíveis a qualquer um? Não seria apenas desleixo de sua parte manter seu corpo fora de forma?

A contenção dos corpos para sua adequação aos espaços sociais ultrapassa as HQs. Esses enunciados também aparecem em outras materialidades compondo o que Foucault chama de dispersão discursiva, ou seja, a sua pulverização em muitos outros artefatos culturais.

$\mathrm{Na}$ esteira desses questionamentos, vemos essas materialidades dispersarem ao pesquisar, por exemplo, no Google por "mulheres executivas". Ali, vemos corpos sempre apresentados como magros e imponentes, para caber não só em um terno (principal invólucro da posição, de preferência preto, porque emagrece), mas nas características que definem uma mulher organizada. Um corpo gordo e sem curvas não passaria uma boa ideia de uma mulher supostamente competente e bem sucedida.

Na moda ditada para essas mulheres não há lugar para um corpo fora do "padrão". Ter um corpo gordo é um "desleixo" desencorajado pelo mercado de trabalho, que encerra as mulheres, constantemente, na posição de sujeito frágil e volátil. Essa ditadura da magreza é particularmente cruel com as mulheres pois boa parte desses acionamentos são a elas endereçados, vinculando a perda de peso não apenas à aquisição de boa saúde como à possibilidade de ter sucesso na vida profissional e pessoal (SARRAF; BASTOS, 2017). 
DOI: http://doi.org/10.46667/renbio.v14i1.534

A contraposição de corpos também é observada em outros espaços da cultura. Gomes e Caminha (2016) apontam várias produções cinematográficas que alcançaram grande sucesso de bilheteria e que trazem em seus enredos o corpo e sua relação com a beleza e a feiura. Os autores afirmam que geralmente é colocado de forma enfática o entendimento de que é decisivo ter um corpo adequado para atingir o sucesso, tanto nas relações sociais quanto profissionais e para alcançar a felicidade.

Nessas produções o corpo valorizado, ou bem dito, apresenta sempre as mesmas características: cabelos louros, magreza, juventude, elevado poder aquisitivo, gosto pela moda e capacidade de sedução. Tais características têm significados próprios e produzem um tipo ideal de corpo poderoso e socialmente aceito. Por outro lado, os corpos mal ditos são o retrato do indesejável. São julgados, mal falados, mal vistos, castigados por destoar do que se espera em termos de atributos físicos. Sobre esses corpos, a produção fílmica aponta que ser gordo é o mesmo que estar fora de moda, ser velho ou ser feio.

O corpo gordo também ganha contornos indesejáveis nas comédias analisadas por Carvalho (2009). Em Norbit (2007), Rasputia, sua esposa, é representada como verdadeira aberração: além de ser gorda ela transgride as normas sociais que geralmente são consideradas essenciais para uma mulher como a regulação e cuidado com sua aparência, a cordialidade, a lealdade de esposa, a honestidade, etc. Em contrapartida, sua rival nos afetos do marido é delicada, atenciosa, carinhosa, usa roupas de cores suaves que lhe acentuam a feminilidade, e para coroar esse conjunto de características desejáveis para uma mulher: ela é magra!

Já Jazmin personagem de O Amor é Cego (2001) e Rose do filme Garotas Formosas (2006) são mulheres cujas identidades foram produzidas em uma rede de significados que embora as posicione como fora da norma por serem gordas, elas apresentam uma grande compensação: são nobres em caráter e é isso que as torna bonitas por dentro. Essa característica é considerada como a grande vantagem que possibilitará com que essas mulheres assumam uma personalidade minimamente interessante para sobreviver no mercado competitivo das atenções masculinas.

No cinema nacional os filmes da série "Minha Mãe é uma Peça” trazem a personagem Marcelina como representação de muitos estereótipos e estigmas sociais associados ao corpo gordo (SOUZA JUNIOR, 2019). Durante todo o filme ela é apresentada pela mãe como preguiçosa, desleixada dona de um corpo que causa desconforto. Seu perfil corporal indesejável é estigmatizado por meio de diálogos que reforçam a discriminação corporal utilizando o humor para reforçar imagens negativas acerca do corpo que está acima do peso.

Essas narrativas que mostram o corpo ideal moldado nos contornos da magreza nos são contadas desde a mais tenra idade. As princesas que conhecemos e que aprendemos a amar são todas desenhadas nesse mesmo padrão. Não há nada fora do lugar: elas são boas e gentis, seus gestos são delicados e ternos, elas enfrentam as dificuldades com resignação e se deslocam com tanta suavidade que parecem que são levadas por correntes de ar. Essas histórias nos ajudam a 
DOI: http://doi.org/10.46667/renbio.v14i1.534

construir os modelos que povoam nosso imaginário e que nos ensinam qual o tipo ideal de corpo feminino (perfeito), com o qual devemos sonhar e desenhar em como devemos ser mulheres no século XXI.

No site da revista Corpo a Corpo ${ }^{12}$, voltada ao público feminino e de circulação nacional vemos seções específicas como "segredos das famosas". "dietas das famosas", "treino das famosas". Todas empenhadas em capturar os olhares e dominar os corpos para bem formatar os modos de vida ensinando as mulheres a ter um "corpo de princesa"! Afinal só é gordo quem quer!

Sant'anna (2014) descreve como a preocupação e o culto ao emagrecimento passam a fazer parte da rotina das mulheres brasileiras a partir da década de 1920 quando as propagandas passam a acionar um tipo de corpo mais esbelto. Nesse período, afirma a autora, já existiam no Brasil mais de 150 laboratórios que, entre outros produtos, fabricavam medicamentos para emagrecer. Mas, é na década seguinte que o corpo feminino passa a ser alvo de intervenções mais direcionadas à sua correção e assim dietas e cintas são as recomendações que devem ser seguidas por aquelas que não desejassem possuir "curvas sedutoras" e "saliências" onde deveriam existir apenas "vales profundos". O excesso de peso e a gordura localizada no ventre e nos seios passaram a caracterizar o que se chamava de um corpo "mal feito".

O enredo sustenta o enunciado de que um corpo magro é um corpo saudável, e esse é o corpo que precisa ser alcançado. Nesse caminho é necessário "examinar sua saúde de verdade!" e achar uma atividade física que proporcione o seu "bem estar!". No caminho de alcançar um corpo magro e saudável, é dito ao corpo gordo que seu lugar é o do desaparecimento. É preciso investir na adoção de um estilo de vida que contemple programas de exercícios e dietas, para a substituição do corpo por um modelo melhor e mais saudável. É como se nos dissessem: tudo bem ser gordo, mas não para sempre!

É assim que o padrão magro que se assenta como molde passando a ser a norma desejável. Nesse processo de normalização, que define um "modelo ótimo" para os corpos, as pessoas passam a se identificar com os corpos "normais-modelos" e também a se perceberem como "anormais-diferentes", fazendo com que trabalhem em seus corpos as mudanças para alcançarem a norma (FOUCAULT, 2008, p.75).

O corpo como objeto e alvo do poder é algo que se fabrica, se manipula, se modela, se treina. É dócil um corpo que pode ser submetido, que pode ser utilizado, que pode ser transformado e aperfeiçoado (Foucault, 1987, p. 117).

\footnotetext{
${ }^{12}$ Informações disponíveis em: corpoacorpo.com.br
} 
DOI: http://doi.org/10.46667/renbio.v14i1.534

De uma massa informe, de um corpo inapto, fez-se a máquina de que se precisa; corrigiram-se aos poucos as posturas; lentamente uma coação calculada percorre cada parte do corpo, se assenhoreia dele, dobra o conjunto, torna-o perpetuamente disponível, e se prolonga, em silêncio, no automatismo dos hábitos (FOUCAULT, 1987, p. 116).

Foucault (1987) afirma que o sucesso do poder disciplinar sobre os corpos se deve ao uso de instrumentos simples e combinados: o olhar hierárquico, a sanção normalizadora e o exame. Pelo olhar hierárquico é preciso ser reconhecido e reconhecer-se e naquilo que falta para atingir o que é considerado como norma. A sanção normalizadora qualifica os comportamentos e os desempenhos a partir de dois valores opostos (bem e mal; maior e menor; melhor e pior), com isso cria as classificações baseadas nas marcas que sinalizam os desvios e que hierarquizam as qualidades. O exame combina as técnicas da hierarquia que vigia e as da sanção que normaliza. É um controle vigilante que fixa as diferenças individuais a partir de um modelo que se espera alcançar e que permite qualificar, classificar e quando necessário, punir os que estão fora do padrão.

Desse modo, a prática de esportes e todas as outras atividades empregadas para "malhar" o corpo visando torná-lo melhor, mais bonito e aceitável, nada mais são que os efeitos que o poder exerce sobre ele. Como explica (FOUCAULT, 1979, p. 83-84), "a ginástica, os exercícios, o desenvolvimento muscular, a nudez, a exaltação do belo corpo... tudo isto conduz ao desejo de seu próprio corpo através de um trabalho insistente, obstinado, meticuloso, que o poder exerceu sobre o corpo". Para Soares $(2008$, p. 80) o esporte realiza uma regulação da vida ao espetacularizar um determinado tipo de corpo, sendo considerado também uma pedagogia higiênica e o símbolo de uma vida "saudável".

Goellner (2000) afirma que a partir dos anos 30 no Brasil, várias ações no campo específico das práticas corporais e esportivas são assumidas pelo Estado. Tomando como base princípios eugenistas que temiam a "degenerescência da raça" ao mesmo tempo que propagavam "o robustecimento da força produtiva necessária ao desenvolvimento da economia nacional", o trabalho corporal é reconhecido como essencial ao desenvolvimento da nação. Sendo assim, a Educação Física e o esporte passam a ser vistos como espaços de intervenção na educação dos cidadãos, no sentido da valorização do corpo esteticamente belo e do aperfeiçoamento físico de corpos saudáveis e aptos, capazes de enfrentar os desafios da vida modernizada.

A popularização da educação física, no entanto, teve seu ápice entre as décadas de 19801990 do século XX, onde o exercício corporal ultrapassou as fronteiras da escola e dos centros especializados para se materializar nas academias de ginástica e na casa das pessoas. Esse movimento foi amplificado por meio de vídeos de exercícios aeróbicos produzidos pelas estrelas de sucesso (como Jane Fonda) que, vestidas em roupas colantes para evidenciar a "boa forma corporal" que desfrutavam, nos ensinavam como deixar a silhueta mais enxuta, sem sair de casa. 
DOI: http://doi.org/10.46667/renbio.v14i1.534

Nessa época, a necessidade de atingir um corpo ideal foi cantada por Marcos Vale em Estrelar $^{13}$, hit de muito sucesso que nos incitava a colocar o corpo em movimento anunciando que "quem não se endireitar, não tem lugar ao sol". O corpo a ser exibido no verão deveria ser "estrelar" e "mais brilhante do que o sol". Antes dele, Olívia Newton-John, emplacou nas paradas de sucesso a música Physical. Embora a letra destoasse completamente da roupa e dos movimentos realizados pela cantora no clip de divulgação da música ${ }^{14}$, a melodia foi utilizada para alavancar e implementar um modo de vida fitness. A força desse discurso de que todo gordo precisa fazer exercícios e emagrecer assenta a magreza como destino ou como característica inata e predeterminada que todas as pessoas gordas precisam atingir e as magras manter.

Todos esses acionamentos capturam em maior proporção as mulheres, uma vez que é muito forte o entendimento de que as preocupações estéticas com o corpo são assuntos destinados, prioritariamente ao gênero feminino. $\mathrm{O}$ levantamento sobre obesidade realizado por Martins (2006) tanto na mídia impressa quanto na televisiva, o dispositivo da magreza aciona mais as mulheres que os homens, pois são elas as mais preocupadas com o excesso de gordura nos seus corpos, são elas que efetivamente fazem do combate à obesidade sua prioridade máxima.

Freire (2011) nos conta que o passado colonial brasileiro era uma "história de gente gorda" e que nessa época a gordura era vinculada à boa saúde e à formosura. Apesar disso, a passagem do século XX para o século XXI marca em nossa sociedade a ressignificação dos seus conceitos de beleza e estética. Contribuiu para isso a classificação da obesidade como doença crônica pela Organização Mundial de Saúde (OMS). A autora explica que a normalidade é determinada de acordo com a época em que se vive e que os padrões e critérios de escolha mudam porque a cultura é dinâmica. Nossos avanços tecnológicos contribuem para definição do que é normal e do que é patológico. A noção de peso ideal só serve para criar idealizações que levam a frustrações e desilusões. Em suas palavras,

O que hoje é considerado bonito, ontem era feio. Com relação ao peso, o processo é idêntico, e talvez valesse a pena lembrar que a diferença reside no quanto de gordura a sociedade valoriza. Em tempos de escassez, as gordinhas de outrora virariam modelo, mas na abundância alimentícia da atualidade, todos querem se livrar das gorduras (FREIRE, 2011 p. 459).

A classificação da obesidade como patologia torna o corpo passível de tratamento e cura. Se vivemos em um mundo lipofóbico, no qual reiteradamente somos ensinados que é errado ser gordo, procuramos por meio da ciência e dos estudos médicos explicações que justifiquem a condição gorda de determinada pessoa, pois ninguém é gordo por que quer. E é exatamente esse o desfecho da história de Isa. Depois de passar por tanto sofrimento é revelado

\footnotetext{
${ }^{13}$ Música pertencente ao álbum "Marcos Valle", do artista de mesmo nome. Lançado em 1983. Composição: Leon Ware, Paulo Sérgio Valle e Marcos Valle.

${ }^{14}$ Material disponível em: https://www.youtube.com/watch?v=6zwPVU92-XQ
} 
DOI: http://doi.org/10.46667/renbio.v14i1.534

que uma disfunção na glândula tireoide (hipotireoidismo) a impede de conseguir perder os quilos indesejados. Assim, Isa é desculpada por sua incapacidade de ter um corpo perfeito, pois não há solução para sua "condição" de pessoa gorda.

Um detalhe bastante interessante que pode ser observado nessas produções é que corpo gordo feminino não atrai a atenção do sexo oposto sendo um corpo que não desperta desejos. $\mathrm{Na}$ história de Isa ela não é cortejada pelos meninos da turma, muito pelo contrário, eles a rejeitam o tempo todo e fazem piadinhas com a forma de seu corpo. Todos duvidam que ela tenha um namorado que realmente goste dela.

Para além dos exercícios e atividades físicas, as dietas também são frequentemente atribuídas ao sujeito gordo como forma possível de alcançar o corpo ideal. Para Andrade (2013, p.115) as dietas dizem do poder disciplinar das ciências nutricionais, que passaram a dar conta do que a população consome. Para a autora junto com o crescimento de um poder disciplinar ligado às dietas, cresce também a oferta de um vasto e diversificado mercado alimentício que procura controlar o corpo e ajustar a vida ao padrão dito saudável. Nesse contexto vemos que mesmo em revistas voltadas para o público infantil, as dietas são apresentadas, sem qualquer tipo de problematização, como alternativa possível para alcançar o corpo ideal.

Aliados aos exercícios, agora as dietas também entram na ordem do discurso corporal nos ensinando o que devemos comer, em quais horários e em quais quantidades. O caminho para conseguir o corpo perfeito envolve muitos sacrifícios englobando agora a restrição de alimentos. Campos et al. (2016) baseados na obra de Vigarello (A história da obesidade) nos contam que século XVII os regimes e práticas de emagrecimento eram citadas com frequência nas cartas, nos rituais e nos relatos e eram socialmente prestigiados. Contudo, não eram recomendações feitas por médicos e não visavam à diminuição de peso, mas, a necessidade de contenção.

Uma redução alimentar era indicada com o objetivo de evitar as enfermidades que uma vida desordenada podia provocar. Os autores contam que nessa época embora a gordura fosse "uma matéria obscura" para a medicina clássica, os "cuidados" com o gordo, se acentuaram. O momento era de valorização dos regimes e de contenção das carnes por meio do uso de cintas e de corpetes. A regra era bem específica: tratava-se de exercer uma constrição física direta para melhor "moldar" as formas e linhas, esperando que se adequassem aos volumes impostos.

Martins (2006, p. 25) emprega o termo dispositivo da magreza para descrever o conjunto formado por essa "rede de inteligibilidade acerca do sujeito gordo, que isola o gordo como um problema e o institui em oposição a um sujeito "normal", saudável e desejável - o magro".

Para Foucault (1979, p. 138) um dispositivo é tudo o que diz (e também o que não é dito) sobre um determinado assunto. É um conjunto bastante heterogêneo que engloba os discursos, instituições, organizações arquitetônicas, decisões regulamentares, leis, medidas administrativas, enunciados científicos, proposições filosóficas, morais, filantrópicas. Em 
DOI: http://doi.org/10.46667/renbio.v14i1.534

outras palavras, o dispositivo é a rede que se pode estabelecer entre todos esses elementos. Como afirma Bastos (2014, p.15), o dispositivo se caracteriza justamente por não ser uma coisa única/unilateral, mas um múltiplo no qual são engendrados e tensionados os mais diversos elementos que o formam.

\section{Para não dizer que não falamos do masculino...}

É certo que os processos de emagrecimento, em sua maioria, são voltados para o corpo feminino. Que a ditadura da magreza captura mais mulheres que homens. Mas, é preciso observar que isso também é reforçado quando colocamos sob a tela (ou dentro do quadrinho) o corpo masculino.

Um detalhe bastante interessante que nos chamou a atenção ao longo de nossas análises é que o corpo gordo feminino não atrai a atenção do sexo oposto sendo um corpo que não desperta desejos. Na história de Isa ela não é cortejada pelos meninos da turma, muito pelo contrário, eles a rejeitam o tempo todo e fazem piadinhas com a forma de seu corpo. Todos duvidam que ela tenha um namorado que realmente goste dela. Em contrapartida, Quinzinho é apoiado incondicionalmente por Magali, sua namorada de infância, além de atrair os olhares de muitas outras meninas apesar de também estar acima do peso.

$\mathrm{Na}$ história "Bullying além do limite" ele também é apresentado como desajeitado e desastrado e se vê sem talento para a prática de esportes (Figura 7). Não querendo atrapalhar, com sua falta de jeito, o jogo de futebol dos meninos, decide "mudar de vida" e resolve investir em aulas de gastronomia. Na escola de culinária, Quinzinho é alvo da violência dos colegas esnobes que ostentam sobrenomes estrangeiros. É interessante observar que as agressões que sofre não são voltadas para o seu aspecto físico, apenas em dois momentos eles é chamado de "bolo fofo" por um dos companheiros, mas isso não toma grandes proporções na trama. Ele é alvo de bullying não por sua aparência, mas por ter um nome comum e que abreviado parece insignificante, por sua origem humilde (filho de pequenos comerciantes de um bairro pobre), por não entender o sotaque francês do professor ou por não estar familiarizado e desconhecer os termos e produtos específicos da "alta gastronomia". 
DOI: http://doi.org/10.46667/renbio.v14i1.534

Figura 6: Trecho da história "Bullying além do limite"

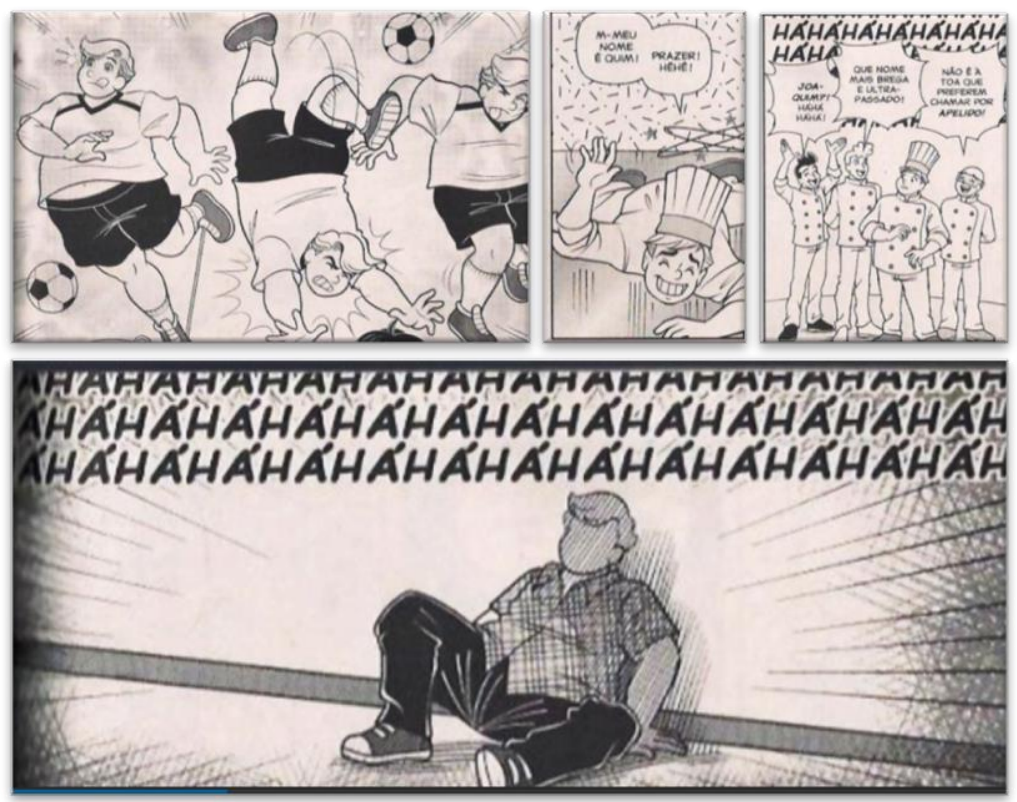

Fonte: Turma da Mônica Jovem, no 45, Panini Comics.

No final da trama, sempre apoiado por Magali, Quinzinho mostra que não vai mais aceitar as provocações e vence seus algozes não com argumentos ou com a faca que sugestivamente aparece em cena bem ao seu alcance, mas, em meio a uma enorme guerra de... comida!

Outro ponto que merece destaque é que ao revelar seu objetivo de cursar gastronomia para Magali ela, com ironia, retruca dizendo que esperava que ele se matriculasse em uma escola de futebol ou em uma academia de ginástica. Ela esperava que Quinzinho investisse seu tempo em atividades que pudessem lhe trazer um corpo diferente, com "mais saúde e qualidade de vida". É de se imaginar que seguindo a carreira gastronômica, aperfeiçoaria suas técnicas culinárias com a tendência de comer ainda mais e com isso estacionasse na sua "condição" de pessoa gorda. Isso não aconteceria se praticasse algum esporte ou frequentasse a academia de ginástica. Vejam que a mudança de vida tão desejada pelo personagem não é associada à escolha de uma carreira ou profissão, mas à mudança das características de seu corpo.

Na coleção Chico Bento Moço, o personagem que traz os mesmos traços de Isa é Jácomo. Seu próprio nome já nos diz muita coisa sobre ele. Embora seja um personagem secundário, ele aparece na capa da primeira revista da série, comendo um sanduíche. E é assim que no desenrolar das tramas ele sempre aparece: comendo alguma coisa! mesmo quando os demais personagens estão envolvidos em várias outras atividades (Figura 6). 
DOI: http://doi.org/10.46667/renbio.v14i1.534

Figura 7: Jácomo, o amigo gordo do Chico Bento Moço

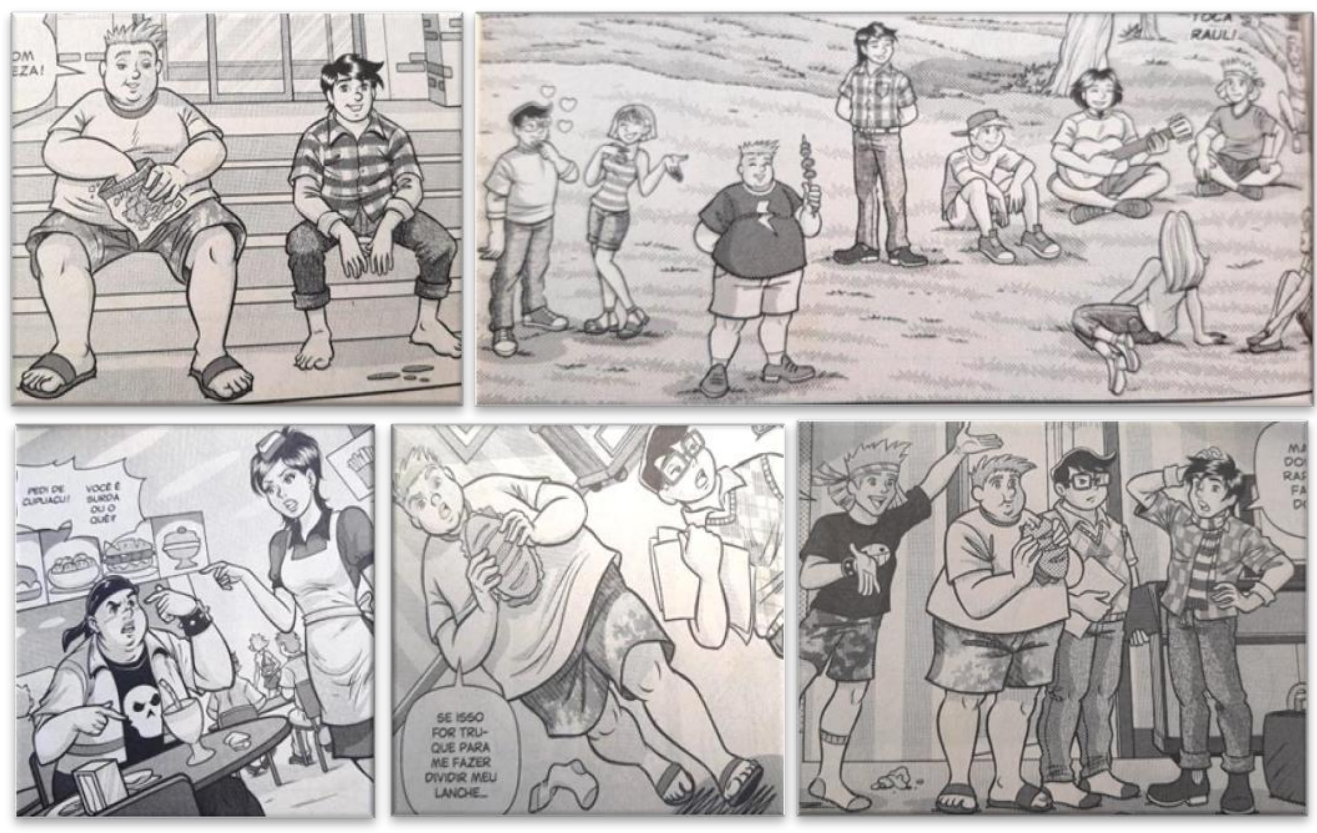

Fonte: Chico Bento Moço, edições 01 (2013), 02 (2013) e 14 (2014), Panini Comics.

Nesta perspectiva o corpo masculino não "confessa" seu corpo como o feminino. As tramas não são voltadas para a prática de exercícios e dieta como nas histórias de Isa, nem mesmo o apelo de Magali o faz ter foco no emagrecimento. O corpo gordo masculino apesar de, também, ser problematizado, não é visto como o lugar de manifestação de uma verdade sobre o corpo como o feminino. Os homens, supostamente, não perdem o "brio" em seus corpos gordos, porém as mulheres se fortaleceriam ajudando umas às outras a emagrecer, o que se transforma facilmente em uma captura do coletivo pela moral.

\section{Por uma educação de ecdises...}

As ecdises são processos de muda. Transformações pelas quais passam algumas espécies de seres vivos em seu hábitat natural. Elas acontecem quando aquilo que protege os animais - o exoesqueleto - já não os comporta mais. Ao se tornar pequeno ele é dispensado, jogado fora, para que em seu lugar, um novo contorno seja fabricado... Esses animais vivem assim, em uma constante troca, muda, transformação, metamorfoseando seus corpos e vidas. Pensando nisso e depois de problematizar as paisagens que nos são reiteradamente apresentadas como naturais, ousamos pensar uma educação em ecdises. 
DOI: http://doi.org/10.46667/renbio.v14i1.534

Essa educação não está preocupada com capas fixas de proteção, em casulos seguros que nos cobrem desde o nascimento e que permanecem até a nossa morte. Uma educação "ectídica" propõe exatamente um caminho inverso, uma busca por uma educação que se atente às singulares existentes em nossas salas de aula, uma educação que não está presa em corpos fixos, mas que acompanha os corpos como eles são: mutáveis, móveis, potentes, transformadores e afirmativos, pois segundo Rago (2009), ao corroborar o pensamento de Deleuze, nos diz que "afirmar é aliviar: não carregar a vida com o peso dos valores superiores, mas criar valores novos que sejam os da vida, que façam a vida leve e ativa" (p. 255). E nada mais ativa que a vida nômade, pois para deslocar-se constantemente é preciso ter a mente em constante movimento, mesmo acampado.

É pensando nessa educação nômade que deixaremos de ser professores-profetas e passaremos a ser professores-militantes (GALLO, 2002). Os professores-profetas são professores que criticam o presente pensando em um futuro novo, são professores que "do alto de sua sabedoria dizem ao outro o que deve ser feito" (idem, p. 170). Os professores-militantes vivem a miséria de suas salas de aula, vivem as situações do deserto de suas escolas e a partir delas criam possibilidades de ser novo, de ser plural.

É isso que propomos após tudo isso, uma educação que não se proponha a apontar modos de existência para as pessoas, que não profetize o que seremos daqui há algumas dezenas de anos, mas, que aposte na singularidade das nossas salas de aulas e de nossos alunos e que deixe viver as ecdises que cada um deseja realizar em seus corpos e em seus caminhos. Que possamos buscar nas ecdises singulares de cada um, construções que sejam coletivas e não separatistas. Que possamos colocar em suspenso todas essas "sínteses acabadas e prontas", como nos diz Foucault (2007, p.24) e assim, suspeitar de tudo aquilo que nos ensinaram, daquilo que ensinamos e acima de tudo, daquilo que achamos que sabemos.

É preciso reinventar nossos modos de ensinar e repensar a forma como lidamos com os corpos-múltiplos da vida docente. Fugir das normatizações para criar, escavar e inventar novos caminhos... Outros caminhos para ser docente, de ensinar e também de aprender... Somente assim recusaremos todas as prescrições e fôrmas de ser gente e passaremos a viver uma educação de ecdises em nossas escolas.

E, assim, quem sabe um dia ao responder à pergunta "o que vocês mudariam na sua aparência?", nossos futuros professores de ciências possam responder "sim" às ecdises, ao nomadismo, à potência da vida, à criação de modos de existência inclassificáveis... 


\section{Referências}

ALCÂNTARA, Cláudia Sales. Histórias em quadrinhos e educação: inovando o currículo. Ceará: Editora da UECE, 2014. (Didática e Prática de Ensino na relação com a escola)

ANDRADE, Sandra Santos. Mídia impressa e educação de corpos femininos. In: LOURO, Guacira Lopes; FELIPE, Jane; GOELLNER, Silvana Vilodre (Org.) Corpo, gênero e sexualidade: um debate contemporâneo na educação. Petrópolis: Vozes, 2013.

BASTOS, Sandra Nazaré Dias. Retrato falado do professor de Biologia: ciência e docência em discurso. Tese (Doutorado em Educação em Ciências e Matemáticas) - Universidade Federal do Pará, Belém, 2014.

BRAGA, Adriana. Corpo, Mídia e Cultura. Razón y Palabra, v. 69, p. VII - 2, 2009.

CAMPOS, Silvana da Silveira; FERREIRA, Francisco Romão; CARVALHO, Maria Claudia da Veiga Soares; KRAEMER, Fabiana Bom; SEIXAS, Cristiane Marques. O estigma da gordura entre mulheres na sociedade contemporânea. In: PRADO, Shirley; AMPAROSANTOS, Lígia; SILVA, Luísa; AMAIZ, Mabel; BOSI, Maria Lúcia. (Org.). Estudos socioculturais em alimentação e saúde: saberes em rede. Rio de Janeiro: EDUERJ, 2016. (Sabor metrópole séries, vol. 5, p. 231-249).

CARVALHO, Eurídice Mota Sobral. Pedagogia do cinema em ação: representações de mulheres gordas em comédias hollywoodianas. Dissertação (Mestrado em Educação) Universidade Luterana do Brasil, Canoas, RS. 2009.

COURTINE, Jean-Jacques. Decifrar o corpo: pensar com Foucault. Petrópolis, RJ: Vozes, 2013.

DULCI, Thomas Stark. Máquinas que desejam: a captura edipiana em inteligência artificial. In: AQUINO, Júlio Groppa; RIBEIRO, Cintya Regina. (Org.). A educação por vir: experiências com o cinema. São Paulo: Cortez, 2011.

FOUCAULT, Michel. A arqueologia do saber. Rio de Janeiro, Forense Universitária, 2007.

FOUCAULT, Michel. Microfísica do Poder. Rio de Janeiro: Edições Graal, 1979.

FOUCAULT, Michel. Segurança, território, população: curso dado no Collége de France (1977-1978). São Paulo: Editora Martins Fontes, 2008.

FOUCAULT, Michel. Vigiar e punir: nascimento da prisão. Petrópolis: Editora Vozes, 1987.

FREIRE, Dirce de Sá. Com açúcar, sem afeto. In: PRIORE, Mary del; AMANTINO, Márcia (Org.). História do Corpo no Brasil. São Paulo: Editora Unesp, 2011.

GALLO, Sílvio. Em torno de uma educação menor. Educação e Realidade, Porto Alegre, n.27, v.2, p.169-178, jul./dez., 2002. 
DOI: http://doi.org/10.46667/renbio.v14i1.534

GARRÉ, Bárbara; VIEIRA, Virgínia; HENNING, Paula. “Alerta global, fim do mundo, a vingança da natureza": enunciações da revista Veja em análise. Revista Eletrônica do Mestrado em Educação Ambiental, p. 261-276, jan./jun. 2014.

GOELLNER, Silvana Vilodre. Mulheres em movimento: imagens femininas na revista Educação Physica. Educação \& Realidade. v.25, n.2, p. 77-94 jul./dez. 2000.

GOMES, Isabelle Sena; CAMINHA, Iraquitan de Oliveira. Os discursos de corpo bem dito, mal dito e não dito: uma análise a partir de filmes. Rev. Bras. Ciênc. Esporte. v.38, n. 4, 2016.

MARCELLO, Fabiana Amorim. Seleção soma e multiplicação: matemáticas do olhar no trabalho com cinema e educação. In: GUIMARÃES, Leandro Belinaso; GUIDO, Lúcia Estevinho; SCARELI, Giovana. (Org.) Cinema, educação e ambiente. Uberlândia: EDUFU, 2013.

MARTINS, Jaqueline. Tudo, menos ser gorda: a literatura infanto-juvenil e o dispositivo da magreza. Dissertação (Mestrado em Educação) - Universidade Federal do Rio Grande do Sul, Porto Alegre, 2006.

MILANEZ, Nilton. Intericonicidade: funcionamento discursivo da memória das imagens. Acta Scientiarum. Language and Culture. Maringá, v.35, n.4, p. 345-355, out. /dez., 2013

OLIVEIRA, Albaneide Cavalcante. O que é ambiente hoje? Quando imagem é enunciado. Dissertação (Mestrado em Educação em Ciências e Matemáticas) - Universidade Federal do Pará, Belém, 2016.

OLIVEIRA, Maria Jaciara de Azeredo. As histórias em quadrinhos como fonte de informação: uma leitura de "Fábulas" no âmbito da Ciência da Informação. 2014. Dissertação (Mestrado em Ciência da Informação) - Universidade Federal Fluminense, 2014.

PIZARRO, Mariana Vaitiekunas. As histórias em quadrinhos e sua relação com o ensino de ciências: aproximações e reflexos nas dez últimas edições do Encontro Nacional de Pesquisa em Educação em Ciências. ENCONTRO NACIONAL DE PESQUISA EM EDUCAÇÃO EM CIÊNCIAS, 11., 2017. Anais do... Florianópolis, 2017.

RAGO, Margareth. Dizer sim à existência. In: RAGO, Margareth; VEIGA-NETO, Alfredo. (Org.). Para uma vida não- fascista. Belo Horizonte: Autêntica, 2009.

SANT'ANNA, Denise Bernuzzi de. A história da beleza no Brasil. São Paulo: Contexto, 2014.

SANTOS-JÚNIOR, Ney Trevas. A influência das histórias em quadrinhos no ensino de matemática: um saber que permite a comunhão do paradidático com o didático numa busca insólita pela mudança da relação tecida entre a criança e esta ciência exata. 2010. Dissertação (Mestrado em Educação) - Universidade do Estado do Rio de Janeiro, 2010. 
DOI: http://doi.org/10.46667/renbio.v14i1.534

SARRAF, Danielle Correa; BASTOS, Sandra Nazaré Dias. Magra e feliz: lições de beleza da revista Sou mais Eu! In: SEMINÁRIO BRASILEIRO DE ESTUDOS CULTURAIS E EDUCAÇÃO, 7.; SEMINÁRIO INTERNACIONAL DE ESTUDOS CULTURAIS E EDUCAÇÃO, 4., 2017. Anais do...Canoas, 2017.

SOARES, Carmen Lúcia. Pedagogias do corpo: higiene, ginásticas, esporte. In: RAGO, Margareth; VEIGA-NETO, Alfredo. (Org.) Figuras de Foucault. Belo Horizonte: Autêntica, 2008.

SOUZA JUNIOR, João Henriques de Sousa. Representações do gordo no cinema nacional: análise de papeis de atores com sobrepeso e obesidade nas produções cinematográficas brasileiras de maior bilheteria. Revista Livre de Cinema, v. 6, n.1, p.4-12, 2019.

SPICACCI, Aline Alkmin Camargo. Tirinhas da Turma da Mônica: tradução do português para a libras por meio da ELiS. Dissertação (Mestrado em Estudos da Tradução) -

Universidade de Brasília, Brasília, 2018.

Recebido em março de 2021. Aprovado em abril de 2021.

Revisão gramatical realizada por: Marcos Allan da Silva Linhares

E-mail: marcosallan.18@gmail.com 